\title{
Treatment of femoral neck fractures: sliding hip screw or cannulated screws? A meta- analysis
}

\author{
Yutong Xia', Wendong Zhang ${ }^{2}$, Zhen Zhang ${ }^{1}$, Jingcheng Wang ${ }^{1,2^{*}}$ and Lianqi Yan ${ }^{2,3^{*}}$
}

\begin{abstract}
Purpose: Femoral neck fractures are still unsolved problems nowadays; sliding hip screw (SHS) and cannulated compression screw (CCS) are the most commonly used devices. We evaluated the clinical outcomes and complications in the treatment of femoral neck fractures between SHS and CCS in this meta-analysis to find which is better.

Methods: We searched PubMed, Embase, Cochrane library up to 24 August 2020 and retrieved any studies comparing sliding hip screw and cannulated compression screw in treatment of femoral neck fractures; the main outcomes and complications were extracted from the studies which were included.

Results: Nine studies involving 1662 patients (828 patients in the SHS group and 834 patients in the CCS group) were included in this study. SHS had higher rate of avascular necrosis (RR $=1.30,95 \% \mathrm{Cl} 1.08-1.56, p=0.005$ ), and CCS had higher rate of implant removal ( $R R=0.63,95 \% \mathrm{Cl} 0.43-0.93, p=0.02)$. No significant statistical difference in non-union, implant failure, infection, replacement, mortality, orthopedic complications, non-orthopedic complications, and total revision between SHS and CCS group.

Conclusion: Both devices have their pros and cons; SHS had a higher rate of avascular necrosis, and CCS had a higher rate of implant removal rate. No significant statistical difference in non-union, implant failure, infection, replacement, mortality, orthopedic complications, non-orthopedic complications, and total revision between SHS and CCS group.
\end{abstract}

Keywords: Femoral neck fracture, Sliding hip screw, Cannulated compression screw, Internal fixation, Metaanalysis

\section{Introduction}

Femoral neck fractures account for more than half percent of all hip fractures; in elderly people, they are generally caused by low energy such as falling, as for young people, they are often caused by high energy like vehicle accidents [1-3]. Femoral neck fractures will be continuously increasing in the next 30 years [4], which will make a great medical and economic burden [5-7]. The

\footnotetext{
* Correspondence: jingchengwang001@163.com; yanlianqi@126.com 'Dalian Medical University, Dalian 116044, Liaoning Province, China

${ }^{2}$ Department of Orthopedics, Northern Jiangsu People's Hospital, Yangzhou 225001, China

Full list of author information is available at the end of the article
}

surgical methods for the treatment of femoral neck fracture are numerous, but they vary according to the patient's age and fracture type [8-10]. American Academy of Orthopedic Surgeons (AAOS) recommends that displaced femoral neck fractures in elderly patients over 80 years of age with weak mobility should receive total hip arthroplasty or hemiarthroplasty to get the best outcomes [11]. For younger patients and undisplaced femoral neck fractures, internal fixation is the best choice. It is less invasive, can preserve the femoral head, and the hip function is better after healing [12]. However, orthopedic surgeons are often perplexed by postoperative

C C The Author(s). 2021 Open Access This article is licensed under a Creative Commons Attribution 4.0 International License, which permits use, sharing, adaptation, distribution and reproduction in any medium or format, as long as you give appropriate credit to the original author(s) and the source, provide a link to the Creative Commons licence, and indicate if changes were made. The images or other third party material in this article are included in the article's Creative Commons licence, unless indicated otherwise in a credit line to the material. If material is not included in the article's Creative Commons licence and your intended use is not permitted by statutory regulation or exceeds the permitted use, you will need to obtain permission directly from the copyright holder. To view a copy of this licence, visit http://creativecommons.org/licenses/by/4.0/. The Creative Commons Public Domain Dedication waiver (http://creativecommons.org/publicdomain/zero/1.0/) applies to the data made available in this article, unless otherwise stated in a credit line to the data. 
complications of internal fixation, such as avascular necrosis, non-union, implant failure, and reoperation [13, 14]. So, we must find the most reliable implant to deal with this kind of fracture, especially for young patients, internal fixation is the first choice. According to a questionnaire study, $47 \%$ of orthopedic surgeon chose anglefixed device (DHS with or without anti-rotation screw) to fix the fracture, while $43 \%$ of surgeon chose cannulated compress screws (CCSs) to solve the problem; these two kinds of implants are the mainstream nowadays [15]. However, there is not any consensus on which is the real gold standard.

We performed this meta-analysis and evaluated the clinical outcomes and complications in the treatment of femoral neck fractures between SHS and CCS to find which is better. This study aimed to provide reliable evidence for the internal fixation treatment of femoral neck fractures.

\section{Materials and methods}

Our study was done according to the preferred reporting items for systematic reviews and meta-analyses (PRIS MA) statement [16].

\section{Literature search}

We searched three electronic databases (PubMed, Embase, Cochrane library) to get all articles on sliding hip screw (SHS or DHS) and cannulated screw for treating femoral neck fracture with the search terms: (sliding hip screw OR dynamic hip screw or cannulated screw) AND (femoral neck fracture OR intracapsular hip fracture) from database established up to 24 August 2020.

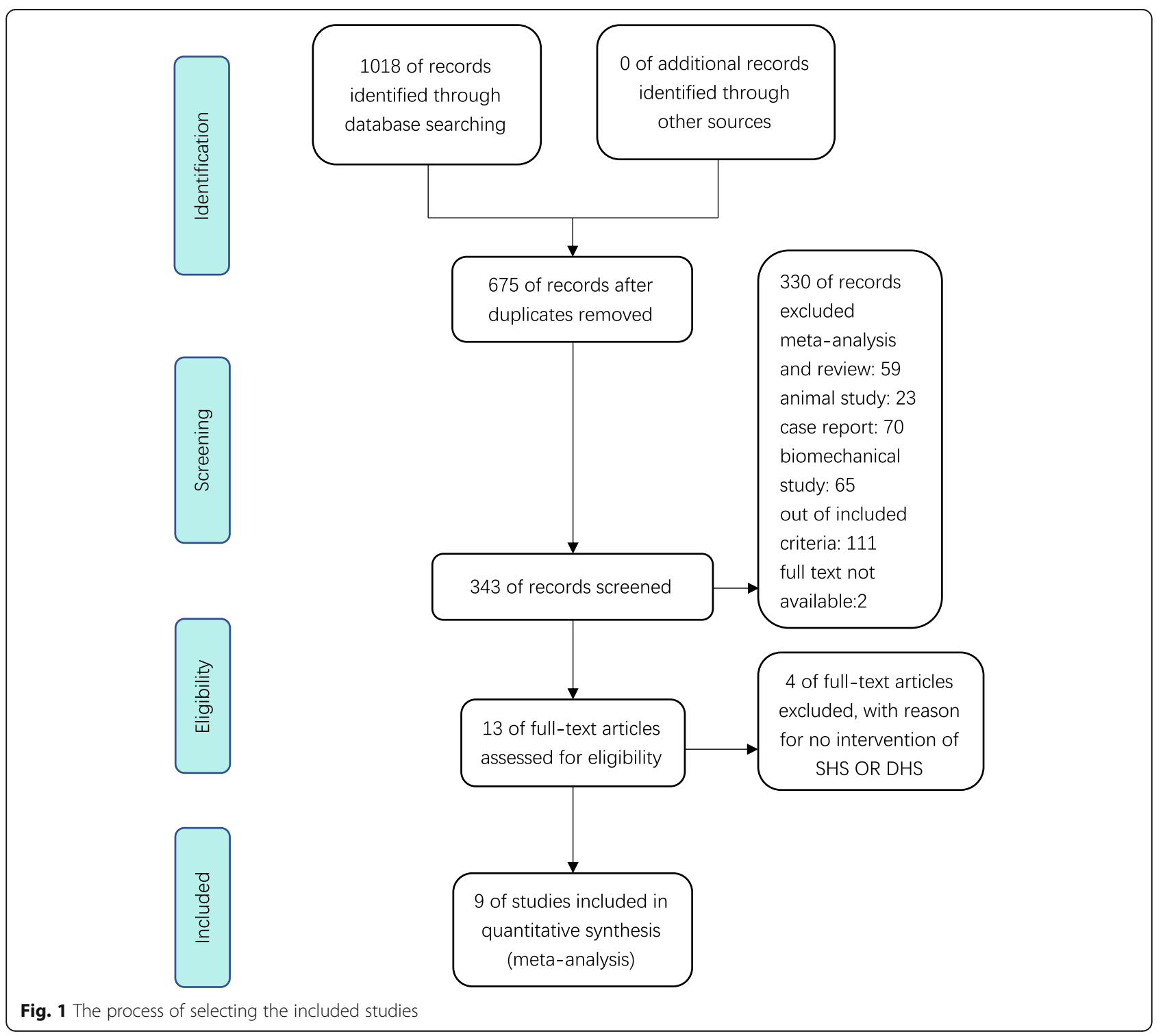


We also did a manual examination to get the whole relevant published or under pressed articles.

\section{Inclusion and exclusion criteria}

Abstract of all acquired and retrieved studies were examined. Studies were included if they were eligible for the requirements: (1) randomized clinical trial studies (RCTs) or controlled clinical trial studies (CCTs); (2) original literature published as full manuscripts; (3) having definite sample size, study time, race, and gender were not limited; (4) comparison of complications such as avascular necrosis, non-union, implant failure, and reoperation or non-orthopedic complications; (5) at least 1 year time to follow-up.

Studies were ineligible for this study if the following existed: (1) non-randomized trials, observational studies, biomechanical studies, and case reports; (2) undefined sample and control source, animal experiments, and non-therapeutic clinical studies; (3) non-original studies and undefined group.

\section{Quality assessment and data extraction}

Two researchers independently appraised the cited studies' quality in line with the Cochrane Collaboration guidelines; items in seven aspects with low, high, or unclear risk of bias were assessed.

Data extraction was carried out critically and independently by two researchers, disputes were solved by the third researcher, the following items were extracted from the included articles: name of the first author, publication year, experiment design, sample size and characteristics, interventions, follow-up time, blood loose (ml), operation time (min), treatment outcome, complications, reoperation rate, and others.

\section{Statistical analysis}

All of the data were analyzed by Review Manager 5.4 (The Cochrane Collaboration, 2020). We used standardized mean differences (SMD) and 95\% confidence intervals $(\mathrm{CI})$ to express continuous data, and risk ratio (RR) with $95 \% \mathrm{CI}$ to present dichotomous data. $p \leq 0.05$ means statistically significant. Then, we appraised heterogeneity by Q testing and $I^{2}$ statistics, if $p \leq 0.10$ or $I^{2}$ $>50 \%$, indicating significant heterogeneity, and then we used the random-effects model to evaluate the system. On the contrary $\left(p>0.10\right.$ or $\left.I^{2}<50 \%\right)$, the fixed-effect model was selected.

\section{Results}

\section{Included articles characteristics}

We searched 3 databases and got 1018 potentially studies; after screening the articles, 9 studies [17-25] containing 1662 patients (828 patients in the SHS group and 834 patients in the CCS group) were included in this study (Fig. 1). The related characteristics were presented in Table 1 .

\section{Quality assessment}

All the include RCT studies reported that they randomly assigned the registered patients to different implant groups, four of the nine studies reported the method of randomization [21, 23-25]. All of the studies had a low risk of bias of selective blinding. Eight trials had a low risk of bias of incomplete outcome of the data $[17,19-25]$. The risk bias summary and risk of bias graph of the included studies were showed in Figs. 2 and 3 , respectively.

\section{Results of the meta-analysis}

Avascular necrosis

Eight studies reported the avascular necrosis rate [17-20, 22-25]. We did the subgroup analysis according to the type of cannulated screw, the different methods of reduction (closed reduction, open reduction, or mixed-method of reduction), and the different types of femoral neck fracture (displaced, undisplaced, and mixed). A sensitivity analysis was done by excluding the FAITH-2 [25] in subgroup type of cannulated

Table 1 Included articles characteristics

\begin{tabular}{llllll}
\hline Study/year & $\mathbf{n}(\mathbf{S H S} / \mathrm{CS})$ & Mean age (SHS/CS) & Gender(M/F) (SHS/CS) & Intervention & Follow-up(month) \\
\hline Linde 1986 & $40 / 47$ & $76 / 76$ & $(16 / 24) /(14 / 33)$ & SHS vs Four CCS & - \\
Madsen 1987 & $51 / 52$ & $75 / 74$ & $(14 / 37) /(11 / 41)$ & SHS vs Four CCS & 24 \\
Kuokkanen1991 & $17 / 16$ & $60 / 72.5$ & - & SHS vs Three CCS & 24 \\
Sorensen 1992 & $35 / 38$ & $75 / 76.14$ & $(10 / 25) /(8 / 30)$ & DHS vs Three GCS & 36 \\
Watson 2012 & $30 / 28$ & $77.9 / 76.7$ & $(6 / 25) /(5 / 24)$ & DHS vs Three CCS & 24 \\
Siavashi 2015 & $30 / 28$ & $30 / 28$ & $(25 / 5) /(21 / 7)$ & DHS vs Three CCS & 36 \\
Gupta 2016 & $40 / 45$ & $40.7 / 39.3$ & $(23 / 17) /(32 / 13)$ & SHS vs Three CCS & 48 \\
FAITH 2017 & $542 / 537$ & $72.2 / 72$ & $(212 / 323) /(210 / 325)$ & SHS vs Three CCS & 24 \\
FAITH-2 2020 & $43 / 43$ & $43 / 39.2$ & $(30 / 13) /(33 / 10)$ & SHS vs Three CCS & 12 \\
\hline
\end{tabular}




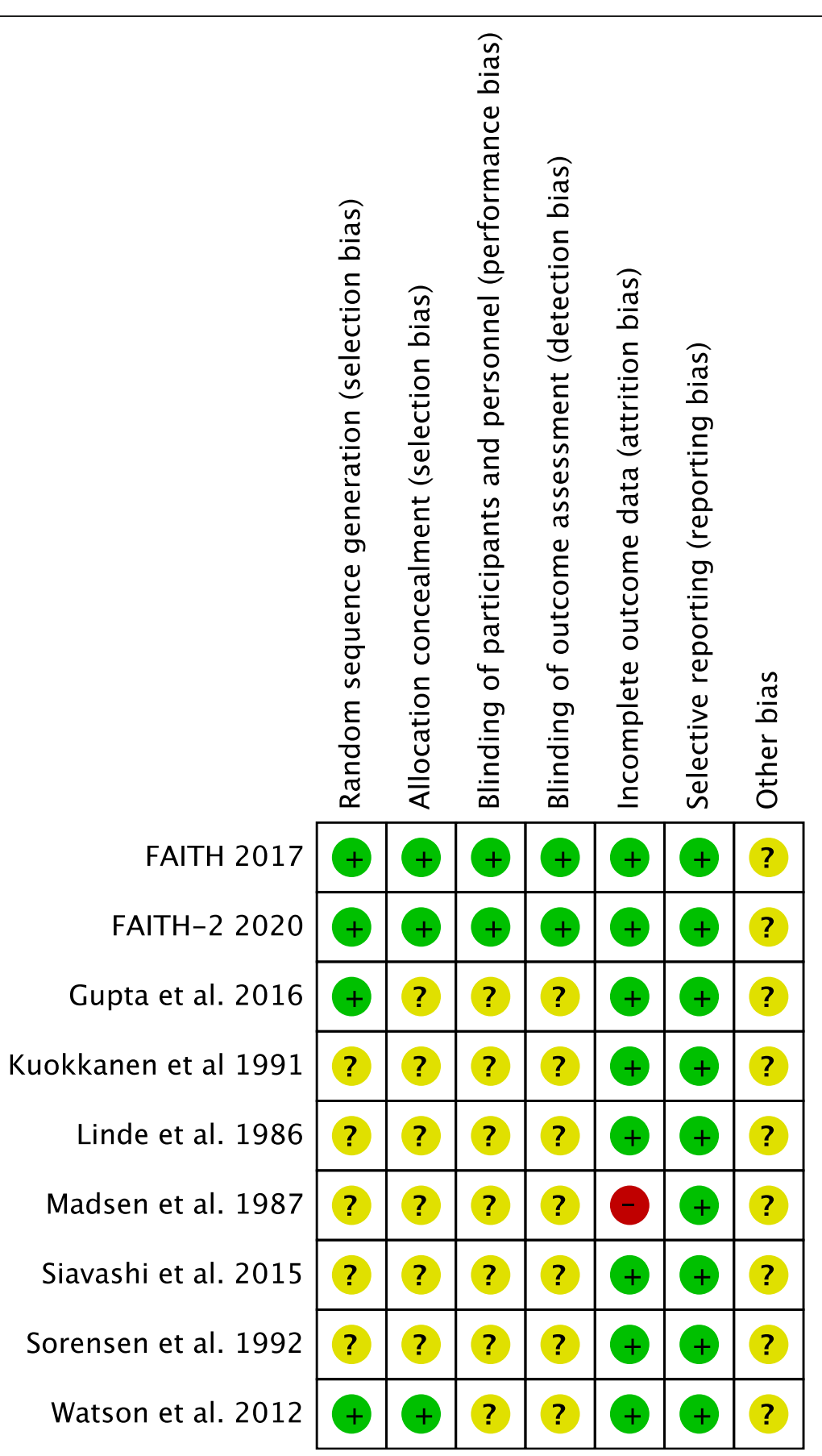

Fig. 2 The risk bias summary of the included studies

screw ( $\left.p=0.17, I^{2}=35 \%\right)$ and mixed-method of reduction $\left(p=0.25, I^{2}=25 \%\right)$, SHS showed a higher avascular necrosis rate in comparison with CCS ( $p=$ 0.009 and $p=0.02$, respectively, Fig. 4). Meanwhile in subgroup displaced femoral neck fracture, they were homogenous $\left(p=0.20, I^{2}=38 \%\right)$, and SHS also showed a higher avascular necrosis rate in comparison with CCS $(\mathrm{RR}=2.40,95 \%$ CI $1.11-5.49$, $p=0.03$, Fig. 4).

\section{Non-union}

Six studies reported the non-union rate $[18,20,21,23-$ $25]$, and they were homogenous ( $p=0.34, I^{2}=12 \%$ ). The result showed no statistical difference in the non- 


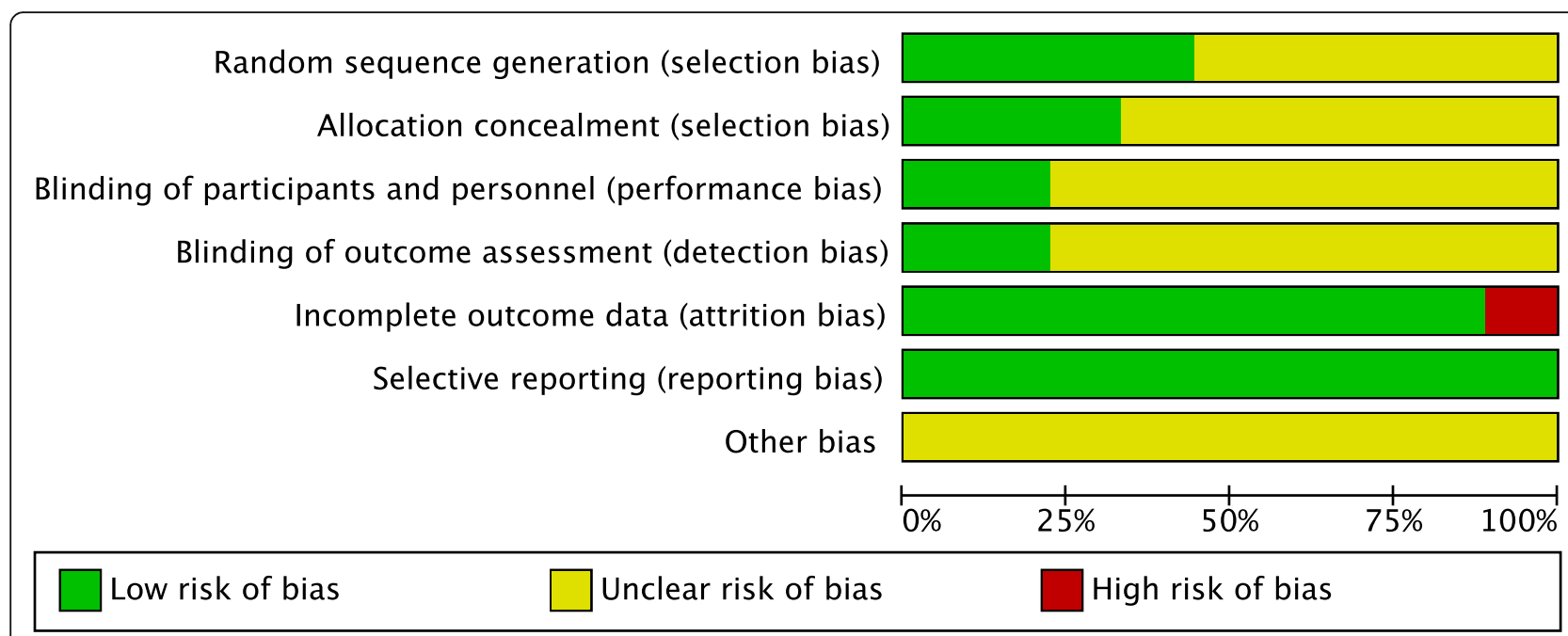

Fig. 3 The risk of bias graph of the included studies

union rate between the two groups $(\mathrm{RR}=1.01,95 \% \mathrm{CI}$ $0.72-1.42, p=0.94$, Fig. 5).

\section{Failure}

Six studies reported the failure rate [19-24]. The studies were homogenous $\left(p=0.34, I^{2}=12 \%\right)$. The result showed not any statistical difference in failure rate between SHS and CCS (RR $=0.81,95 \%$ CI 0.56-1.17, $p=0.26$, Fig. 6).

\section{Infection}

Six studies reported the infection rate [18, 19, 22-25]. The studies were homogenous $\left(p=0.50, I^{2}=0 \%\right)$. The result presented no statistical difference in infection rate between SHS and CCS (RR $=1.65,95 \%$ CI 0.79-3.45, $p=0.19$, Fig. 7).

\section{Implant removal}

Seven studies reported the implant removal rate [18$21,23-25]$. There was heterogeneity across the seven studies $\left(p=0.04, I^{2}=54 \%\right)$. So, the sensitivity analysis was conducted by excluding Kuokkanen et al. [19], then the remaining studies were homogeneous $\left(p=0.18, I^{2}=34 \%\right)$. CCS shown higher implant removal rate compared to SHS $(\mathrm{RR}=0.63,95 \% \mathrm{CI}$ 0.43-0.93, $p=0.02$, Fig. 8).

\section{Replacement}

Eight studies reported the replacement rate [18-25]. And the studies did not have any heterogeneity $(p=$ $\left.0.22, I^{2}=26 \%\right)$. The result indicated no statistical difference in replacement rate between the two groups $(\mathrm{RR}=$ 1.16, 95\% CI 0.91-1.49, $p=0.22$, Fig. 9).

\section{Mortality}

Four studies reported the mortality rate [19-21, 24]. Only a little heterogeneity was found between the studies $\left(p=0.09, I^{2}=54 \%\right.$ ), and we used the randomeffect model to merge the data, and indicated no statistical difference in mortality rate between two groups (RR $=1.27,95 \%$ CI 0.68-2.36, $p=0.45$, Fig. 10).

\section{Orthopedic complications}

All nine articles presented the orthopedic complications post-operation; there was heterogeneity among them $(p$ $\left.=0.003, I^{2}=65 \%\right)$, so the data were merged using a random-effect model and show no statistical difference in postoperative orthopedic complications between two groups $(\mathrm{RR}=0.88,95 \% \mathrm{CI} 0.58-1.33, p=0.55$, Fig. 11).

\section{Non-orthopedic complications}

Only three studies mentioned the non-orthopedic complications after operation [19, 21, 24], and they were homogenous $\left(p=0.27, I^{2}=23 \%\right)$. The result showed no statistical difference in replacement rate between SHS and CCS ( $\mathrm{RR}=0.95,95 \%$ CI 0.77-1.18, $p=0.64$, Fig. 12).

\section{Total revision}

Eight studies reported the revision rate after internal fixation of femoral neck fracture s[18-25]. We found a little heterogeneity between the studies $\left(p=0.05, I^{2}=\right.$ $51 \%$ ) and used the random-effect model to pool the data, result indicated no statistical difference in revision rate between the two groups ( $\mathrm{RR}=0.97,95 \%$ CI $0.64-1.45, p$ $=0.87$, Fig. 13).

\section{Discussion}

Femoral neck fractures need an acute operation, accurate anatomical reduction, and stiff internal fixation. Treatment therapy of femoral neck fracture depends on the age of patients and the classification; internal fixation is the priority of young patients and also a good choice 


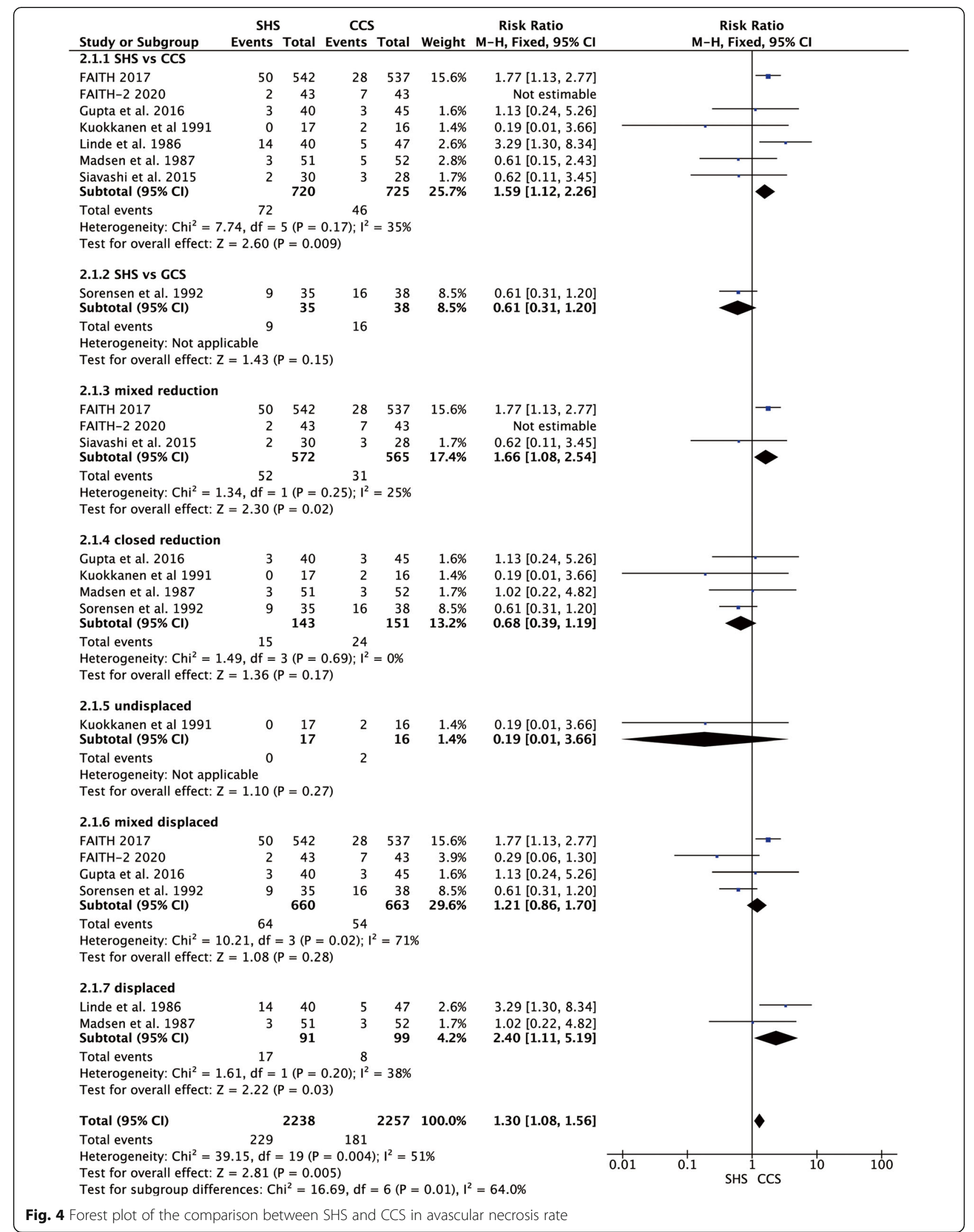




\begin{tabular}{|c|c|c|c|c|c|c|c|c|c|c|}
\hline Study or Subgroup & \multicolumn{2}{|c|}{ SHS } & \multicolumn{2}{|l|}{ CCS } & Weight & $\begin{array}{c}\text { Risk Ratio } \\
\text { M-H, Fixed, } 95 \% \mathrm{Cl} \\
\end{array}$ & \multicolumn{4}{|c|}{$\begin{array}{c}\text { Risk Ratio } \\
\text { M-H, Fixed, 95\% Cl }\end{array}$} \\
\hline FAITH 2017 & 33 & 542 & 33 & 537 & $55.3 \%$ & $0.99[0.62,1.58]$ & & & & \\
\hline FAITH-2 2020 & 4 & 43 & 3 & 43 & $5.0 \%$ & $1.33[0.32,5.61]$ & & & & \\
\hline Gupta et al. 2016 & 5 & 40 & 8 & 45 & $12.5 \%$ & $0.70[0.25,1.98]$ & & & - & \\
\hline Madsen et al. 1987 & 17 & 51 & 10 & 52 & $16.5 \%$ & $1.73[0.88,3.42]$ & & & $\rightarrow$ & \\
\hline Sorensen et al. 1992 & 1 & 35 & 4 & 38 & $6.4 \%$ & $0.27[0.03,2.31]$ & & & & \\
\hline Watson et al. 2012 & 0 & 30 & 2 & 28 & $4.3 \%$ & $0.19[0.01,3.73]$ & & & & \\
\hline Total $(95 \% \mathrm{Cl})$ & & 741 & & 743 & $100.0 \%$ & $1.01[0.72,1.42]$ & & & & \\
\hline Total events & 60 & & 60 & & & & & & & \\
\hline $\begin{array}{l}\text { Heterogeneity: } \mathrm{Chi}^{2}= \\
\text { Test for overall effect }\end{array}$ & $\begin{array}{l}5.71, d f= \\
Z=0.08\end{array}$ & $\begin{array}{l}=5(P= \\
(P=0 .\end{array}$ & $\begin{array}{l}=0.34) ; 1^{2} \\
.94)\end{array}$ & $2=12 \%$ & & & 0.005 & 0.1 & SHS $^{1}$ CCS & 200 \\
\hline
\end{tabular}

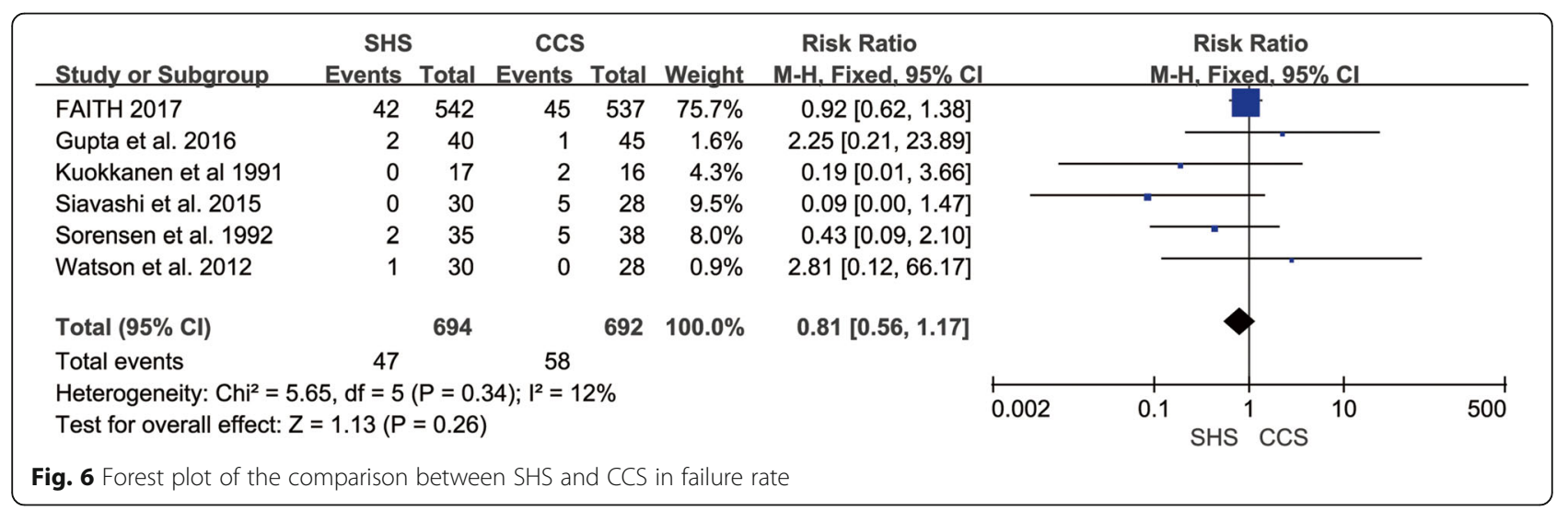

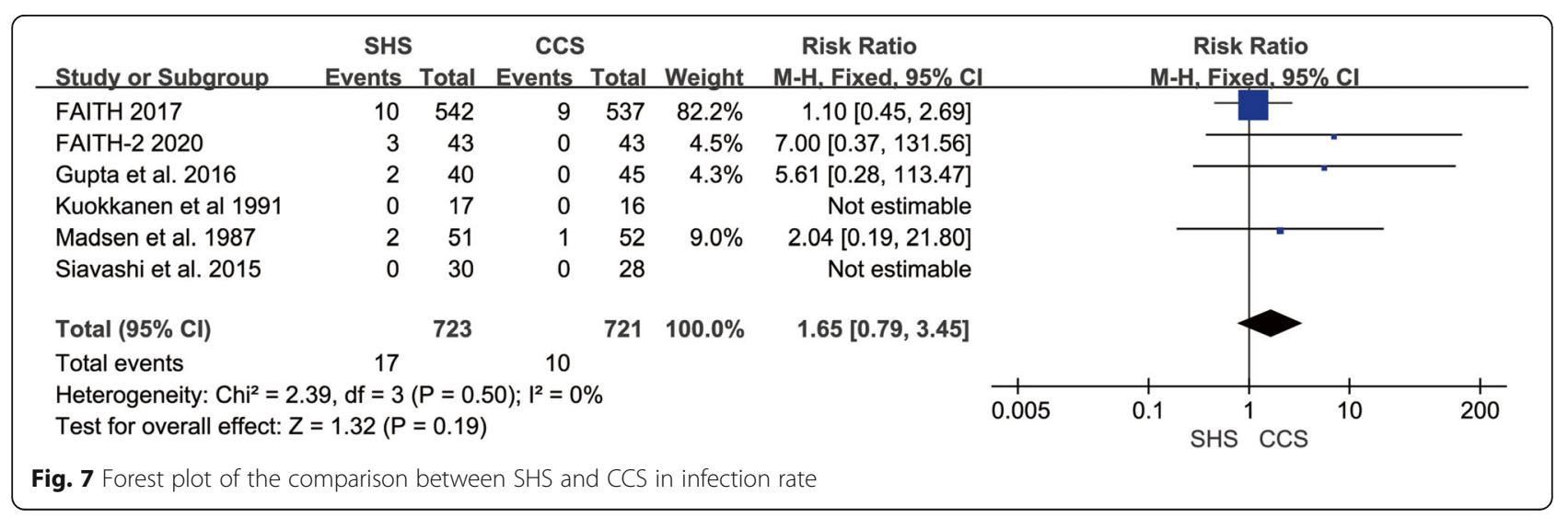




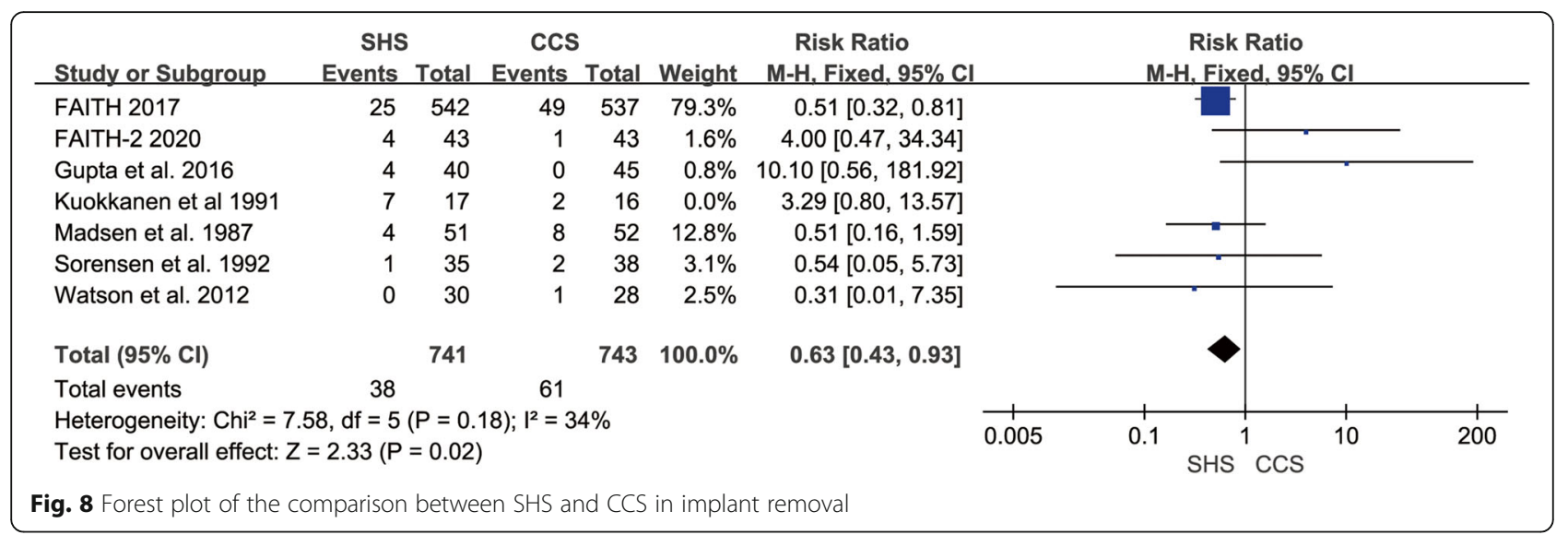

for active elderly. Arthroplasty is the ultimate choice when internal fixation failed or complications occurred [26]. SHS and CCS are the most commonly used implants nowadays, but both of them have the disadvantage.

In this meta-analysis, we can indicate that the avascular necrosis rate was higher in the SHS group, and the implant removal rate was higher in the CCS group. While no significant statistical difference between the SHS and CCS groups in terms of non-union, implant failure, infection, replacement, mortality, orthopedic complications, nonorthopedic complications, and total revision. We defined orthopedic complications like avascular necrosis, nonunion, malunion, delay union, implant cut-out (penetration), implant failure, and periprosthetic fractures. Nonorthopedic complications included cardiovascular disease, gastrointestinal symptoms, pneumonia, urinary infection, deep vein thrombosis, and other diseases. Total revision referred to total arthroplasty, hemiarthroplasty, refixation, and removal of the implant.

As for avascular necrosis of the femoral head, when rotating in the lag screw of SHS or beating in the blade screw of DHS, the rotation strength may cause the femoral head displaced then influence the blood supply it.
Besides, according to the subgroup analysis, the type of femoral neck fracture and the operation mode also has an impact on the blood supply of the femoral head; displaced fracture and open reduction would cause a higher rate of avascular necrosis when using SHS or DHS to deal with it compared with CCS. The Gouffon screw is a kind of partly threaded lag screw with a small diameter; the author said it was difficult to decide the length of the Gouffon screw, and changed screw led to damage to the cancellated bone of the femoral head [20]. Another reason that caused the failure is that small diameter screws cannot hold the trabecular bone strength fully [27], so we did the subgroup analysis and reduced the heterogeneity. The reduction method also influences the prognosis of a femoral neck fracture, and open reduction is associated with a high rate of complications [28]; all the studies except FAITH-2 done almost close reduction; however, in FAITH-2, open reduction was used in the majority (55.8\%), which caused bias and we excluded it when analyzing avascular necrosis. Therefore, we should choose minimally invasive technology to maximize the protection of femoral head blood supply, combined with the concept of systematic treatment to shorten the length of hospital stay and speed up rehabilitation $[29,30]$.

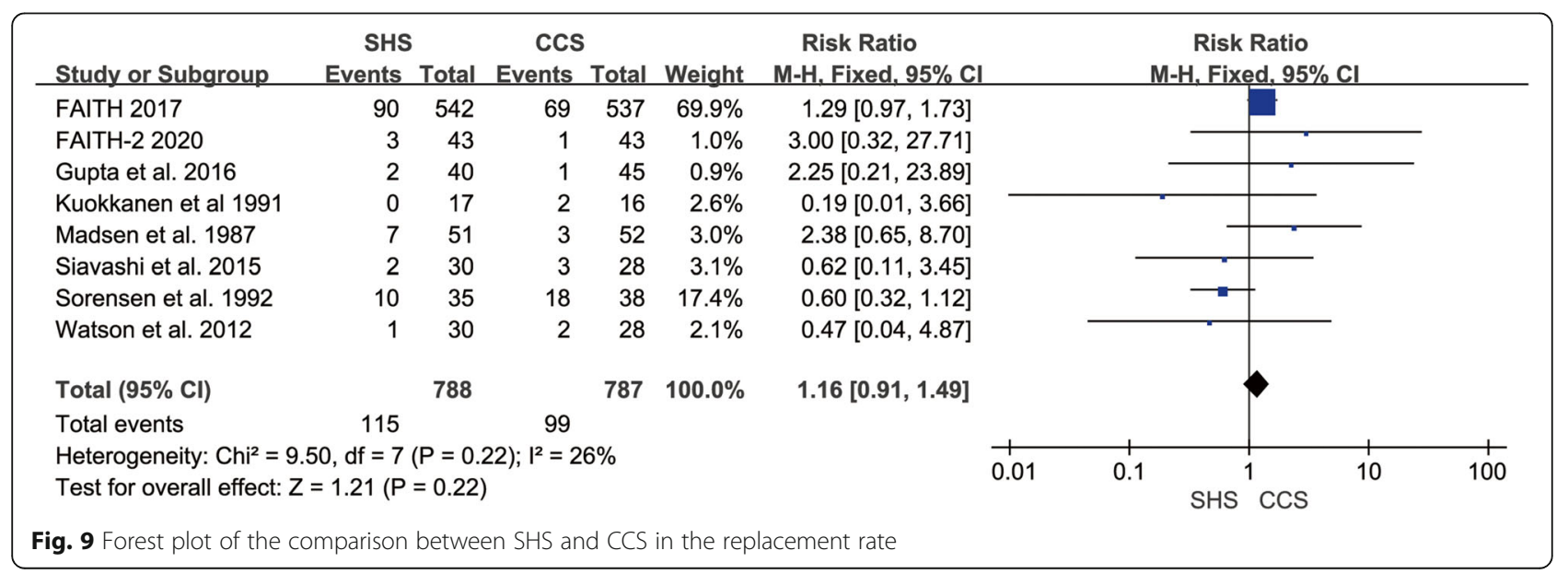




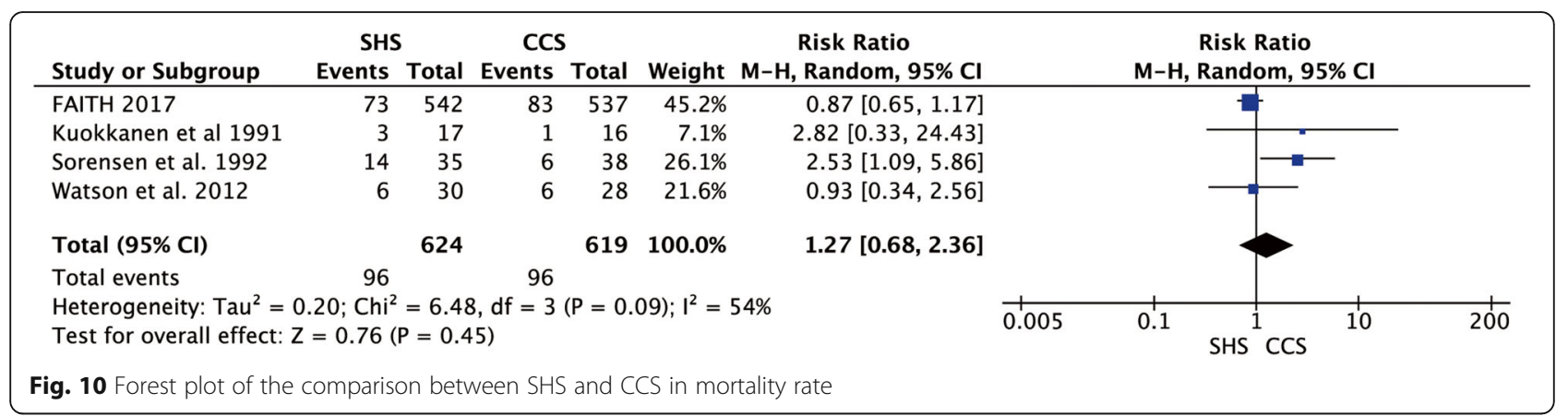

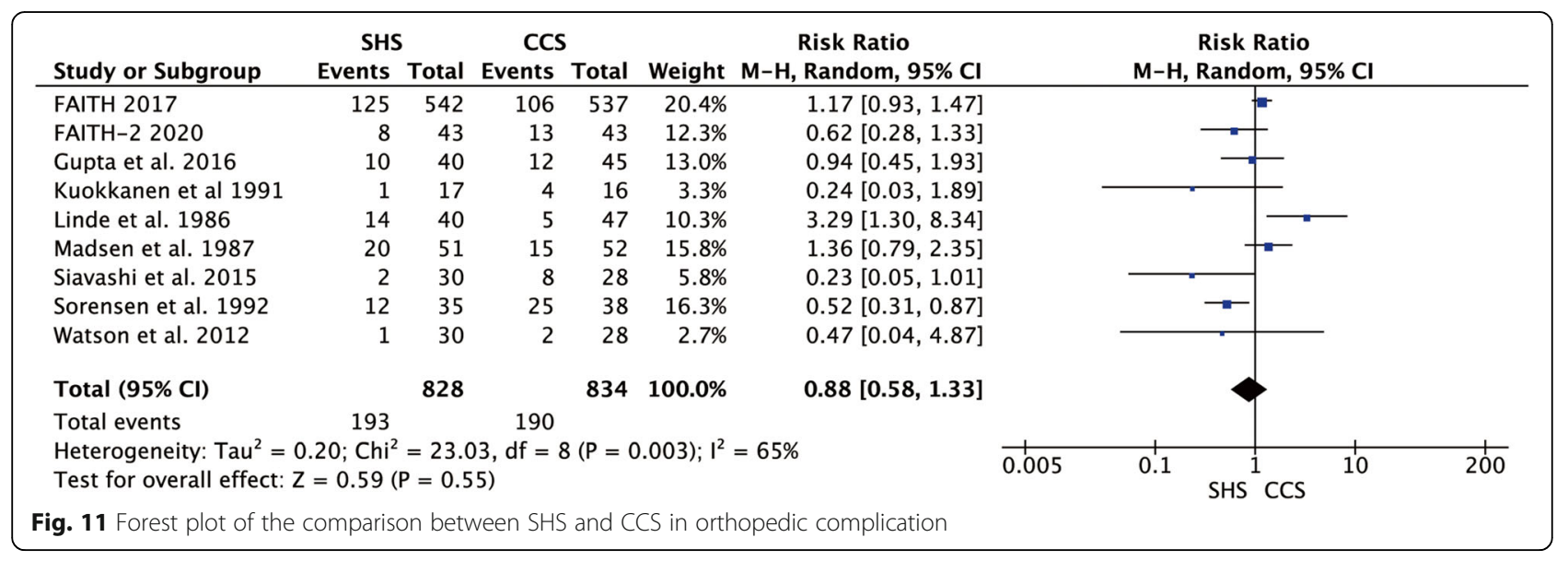

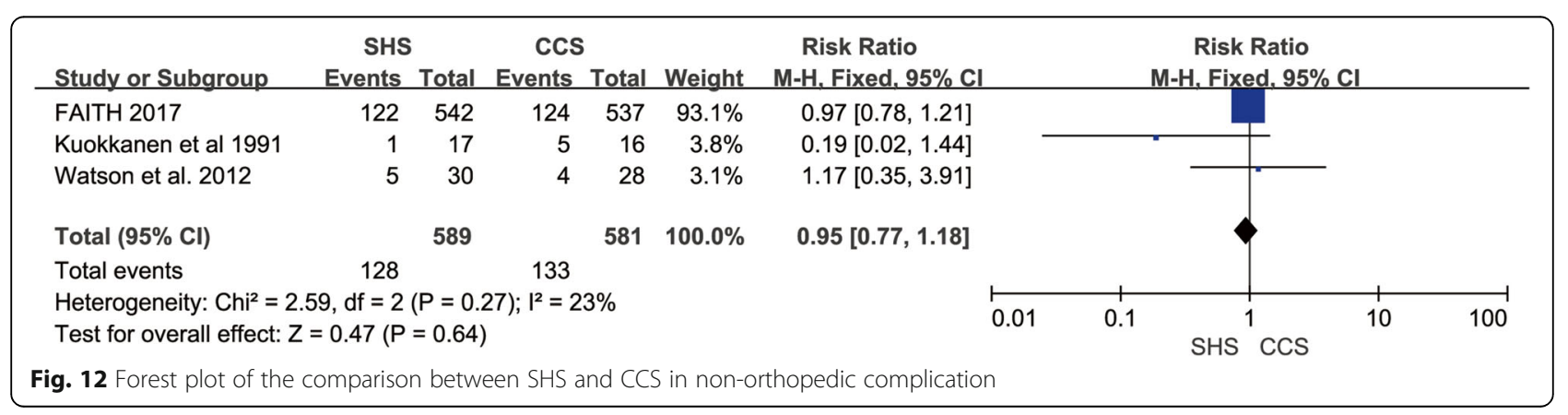




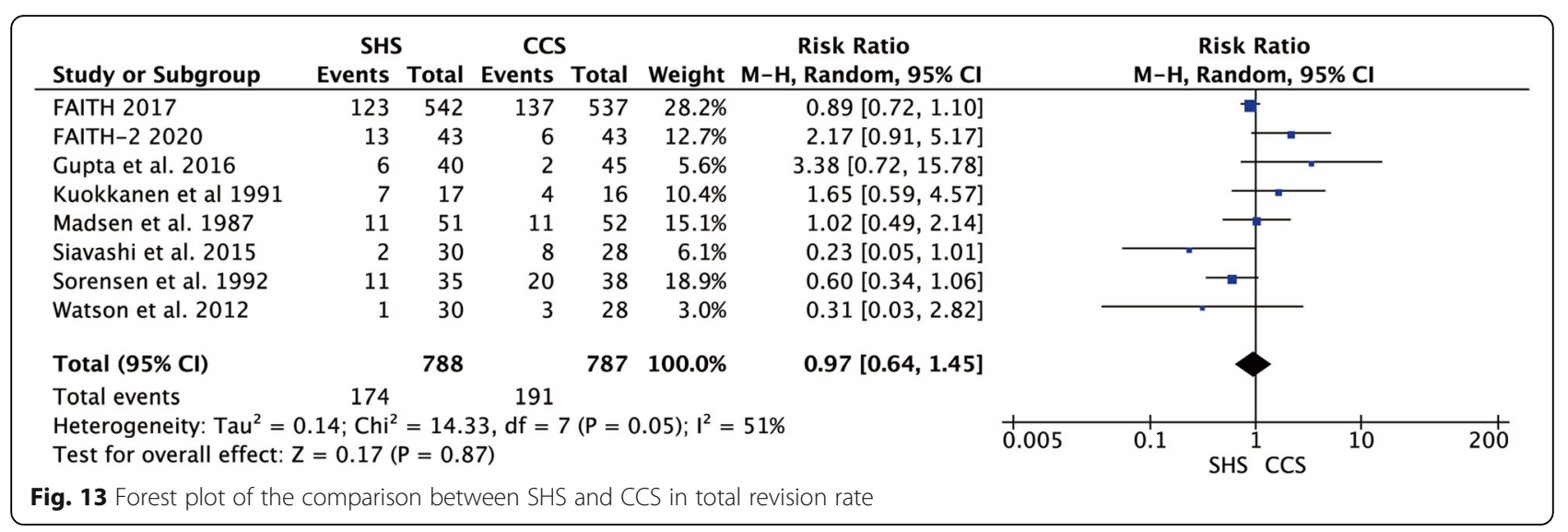

Dynamic compression occurred during the healing of femoral neck fracture when using SHS or CCSs, causing a shortening of the femoral neck. CCSs would back-out from the lateral cortex make locally uncomfortable, while SHS has a telescope-like structure, the blade or lag screw back-out within the sleeve, little protrusion happened in the local place, thus the implant removal was higher in the CCS group.

Different from the published articles, we included in the latest RCT article, and we also did the subgroup analysis according to the type of femoral neck fracture, type of cannulated screws, and the operation mode to find out the factors that affect the final results, making the results more accurate. Meanwhile, the time duration post-trauma of patients in the included study was less than $72 \mathrm{~h}$, and the RCT study had the highest level of evidence to minimize the risk of bias.

Both SHS and CCS have their pros and cons; so, we can combine the merit of them and design new implants with the ability such as minimally invasive, anti-rotation, and angle stable [31], making less influence on the blood supply of femoral neck and can realize instant compression. Restricting dynamic compression is still an unsolved problem.

\section{Limitations}

First, a small number of studies were included in the meta-analysis, and some trials did not report the exact random methods that would cause a certain degree of bias. The following time of included trials was different; long-term observation would find more complications.

Second, the original data of included studies were insufficient to meet the Gaussian distribution and would make bias to the analysis; we could not analyze the Harris hip score, blood loss, and operation time, though we had the formula to calculate the mean and standard deviation.
Finally, we did not analyze the outcomes of different age and sex.

\section{Conclusions}

This meta-analysis provides evidence that SHS has a higher rate of avascular necrosis, while CCS has a higher rate of implant removal rate. There is no difference between the two groups in non-union, failure, infection, replacement, mortality, orthopedic complications, nonorthopedic complications, and total revision.

\section{Abbreviations}

SHS: Sliding hip screw; CCS: Cannulated compression screw; AAOS: American Academy of Orthopedic surgeons; DHS: Dynamic hip screw;

RCTs: Randomized clinical trial studies; CCTs: Controlled clinical trial studies; SMD: Standardized mean differences; $\mathrm{Cl}$ : Confidence intervals

\section{Acknowledgements}

Not applicable.

\section{Authors' contributions}

All authors reviewed and accepted the final manuscript. Yutong Xia: study design, data analysis, data collections, and writing; Wendong Zhang: data analysis and data collections; Zhen Zhang: data analysis and writing; Lianqi Yan: study design, data analysis. Yutong Xia and Lianqi Yan contributed equally to this work.

\section{Funding}

This study was supported by the National Natural Science Foundation of China (Grant No. 81772332), Jiangsu Provincial Medical Innovation Team (Grants\#CXTDB2017004).

Availability of data and materials

All data generated or analyzed during this study are included in this published article.

Ethics approval and consent to participate Not applicable.

\section{Consent for publication}

Not applicable.

\section{Competing interests}

The authors declare that they have no competing interests.

\section{Author details}

'Dalian Medical University, Dalian 116044, Liaoning Province, China.

${ }^{2}$ Department of Orthopedics, Northern Jiangsu People's Hospital, Yangzhou 
225001, China. ${ }^{3}$ The second Xiangya hospital of Central South University, Changsha, Hunan 410012, China.

Received: 23 October 2020 Accepted: 27 December 2020

Published online: 14 January 2021

\section{References}

1. Rose S, Maffulli N. Hip fractures. An epidemiological review. Bull Hosp Jt Dis. 1999:58:197-201.

2. Støen RO, Nordsletten L, Meyer HE, Frihagen JF, Falch JA, Lofthus CM. Hip fracture incidence is decreasing in the high incidence area of Oslo, Norway. Osteoporos Int. 2012;23:2527-34.

3. Douglas S, Bunyan A, Chiu KH, Twaddle B, Maffulli N. Seasonal variation of hip fracture at three latitudes. Injury. 2000;31:11-9.

4. Cooper C, Campion G, Melton LJ. Hip fractures in the elderly: a world-wide projection. Osteoporos Int. 1992;2:285-9.

5. Shabat S, Mann G, Nyska M, Maffulli N. Scoring systems to evaluate elderly patients with hip fractures. Disabil Rehabil. 2005;27:1041-4.

6. Kannus P, Parkkari J, Sievänen $\mathrm{H}$, Heinonen $\mathrm{A}$, Vuori I, Järvinen M. Epidemiology of hip fractures. Bone. 1996;18:57S-63S.

7. Johnell O, Kanis JA. An estimate of the worldwide prevalence and disability associated with osteoporotic fractures. Osteoporos Int. 2006;17:1726-33.

8. Rupprecht M, Grossterlinden L, Sellenschloh K, Hoffmann M, Püschel K, Morlock $\mathrm{M}$, et al. Internal fixation of femoral neck fractures with posterior comminution: a biomechanical comparison of $\mathrm{DHS}^{\oplus}$ and Intertan nail ${ }^{\oplus}$. Int Orthop. 2011:35:1695-701.

9. Rogmark C, Carlsson A, Johnell O, Sernbo I. A prospective randomised trial of internal fixation versus arthroplasty for displaced fractures of the neck of the femur. Functional outcome for 450 patients at two years. J Bone Joint Surg Br. 2002;84:183-8.

10. Yih-Shiunn L, Chien-Rae H, Wen-Yun L. Surgical treatment of undisplaced femoral neck fractures in the elderly. Int Orthop. 2007;31:677-82.

11. Brox WT, Roberts KC, Taksali S, Wright DG, Wixted JJ, Tubb CC, et al. The American Academy of Orthopaedic Surgeons Evidence-Based Guideline on Management of Hip Fractures in the Elderly. J Bone Joint Surg Am. 2015;97: 1196-9.

12. Zielinski SM, Meeuwis MA, Heetveld MJ, Verhofstad MHJ, Roukema GR, Patka $\mathrm{P}$, et al. Adherence to a femoral neck fracture treatment guideline. Int Orthop. 2013;37:1327-34.

13. Liporace $F$, Gaines R, Collinge $C$, Haidukewych GJ. Results of internal fixation of Pauwels type-3 vertical femoral neck fractures. J Bone Joint Surg Am. 2008:90:1654-9.

14. Estrada LS, Volgas DA, Stannard JP, Alonso JE. Fixation failure in femoral neck fractures. Clin Orthop Relat Res. 2002. p. 110-8.

15. Luttrell $\mathrm{K}$, Beltran M, Collinge CA. Preoperative decision making in the treatment of high-angle "vertical" femoral neck fractures in young adult patients. An expert opinion survey of the Orthopaedic Trauma Association's (OTA) membership. J Orthop Trauma. 2014;28:e221-5.

16. Moher D, Liberati A, Tetzlaff J, Altman DG, PRISMA Group. Preferred reporting items for systematic reviews and meta-analyses: the PRISMA statement. J Clin Epidemiol. 2009;62:1006-12.

17. Linde F, Andersen E, Hvass I, Madsen F, Pallesen R. Avascular femoral head necrosis following fracture fixation. Injury. 1986;17:159-63.

18. Madsen F, Linde F, Andersen E, Birke H, Hvass I, Poulsen TD. Fixation of displaced femoral neck fractures. A comparison between sliding screw plate and four cancellous bone screws. Acta Orthop Scand. 1987:58:212-6.

19. Kuokkanen H, Korkala O, Antti-Poika I, Tolonen J, Lehtimäki MY, Silvennoinen T. Three cancellous bone screws versus a screw-angle plate in the treatment of Garden I and II fractures of the femoral neck. Acta Orthop Belg. 1991;57:53-7.

20. Sørensen JL, Varmarken JE, Bømler J. Internal fixation of femoral neck fractures. Dynamic Hip and Gouffon screws compared in 73 patients. Acta Orthop Scand. 1992;63:288-92.

21. Watson A, Zhang Y, Beattie S, Page RS. Prospective randomized controlled trial comparing dynamic hip screw and screw fixation for undisplaced subcapital hip fractures. ANZ J Surg. 2013;83:679-83.

22. Siavashi B, Aalirezaei A, Moosavi M, Golbakhsh MR, Savadkoohi D, Zehtab MJ. A comparative study between multiple cannulated screws and dynamic hip screw for fixation of femoral neck fracture in adults. Int Orthop. 2015;39: 2069-71.
23. Gupta M, Arya R-K, Kumar S, Jain V-K, Sinha S, Naik A-K. Comparative study of multiple cancellous screws versus sliding hip screws in femoral neck fractures of young adults. Chin J Traumatol. 2016;19:209-12.

24. Fixation using Alternative Implants for the Treatment of Hip fractures (FAIT H) Investigators. Fracture fixation in the operative management of hip fractures (FAITH): an international, multicentre, randomised controlled trial. Lancet. 2017;389:1519-27.

25. Slobogean GP, Sprague S, Bzovsky S, Scott T, Thabane L, Heels-Ansdell D, et al. Fixation Using Alternative Implants for the Treatment of Hip Fractures (FAITH-2): the clinical outcomes of a multicenter $2 \times 2$ factorial randomized controlled pilot trial in young femoral neck fracture patients. J Orthop Trauma. 2020;34:524-32.

26. Bhandari M, Devereaux PJ, Tornetta P, Swiontkowski MF, Berry DJ, Haidukewych G, et al. Operative management of displaced femoral neck fractures in elderly patients. An international survey. J Bone Joint Surg Am. 2005;87:2122-30.

27. Maurer SG, Wright KE, Kummer FJ, Zuckerman JD, Koval KJ. Two or three screws for fixation of femoral neck fractures? Am J Orthop (Belle Mead NJ). 2003:32:438-42.

28. Patterson JT, Ishii K, Tornetta P, Leighton RK, Friess DM, Jones CB, et al. Open reduction is associated with greater hazard of early reoperation after internal fixation of displaced femoral neck fractures in adults 18-65 years. J Orthop Trauma. 2020;34:294-301.

29. Ho M, Garau G, Walley G, Oliva F, Panni AS, Longo UG, et al. Minimally invasive dynamic hip screw for fixation of hip fractures. Int Orthop. 2009;33: $555-60$.

30. Aletto C, Aicale R, Pezzuti G, Bruno F, Maffulli N. Impact of an orthogeriatrician on length of stay of elderly patient with hip fracture. Osteoporos Int. 2020;31:2161-6.

31. Aicale R, Tarantino D, Oliviero G, Maccauro G, Peretti GM, Maffulli NO. nil Anteversa ${ }^{\oplus}$ mini-plate for stable hip fracture: first experience considerations and outcomes. J Biol Regul Homeost Agents. 2019;33:147-54.

\section{Publisher's Note}

Springer Nature remains neutral with regard to jurisdictional claims in published maps and institutional affiliations.

Ready to submit your research? Choose BMC and benefit from:

- fast, convenient online submission

- thorough peer review by experienced researchers in your field

- rapid publication on acceptance

- support for research data, including large and complex data types

- gold Open Access which fosters wider collaboration and increased citations

- maximum visibility for your research: over $100 \mathrm{M}$ website views per year

At BMC, research is always in progress.

Learn more biomedcentral.com/submissions 